\section{SUPRACLAVICULAR ANESTHETIZATION OF THE BRACHIAL PLEXUS}

A CASE OF COLLAPSE FOLLOWING its ADMINistration *

$$
\begin{gathered}
\text { HAROLD NEUHOF, M.D. } \\
\text { NEW YORK }
\end{gathered}
$$

About three years ago Kulenkampff ${ }^{1}$ described a method of anesthetizing the upper extremity by injecting novocain solutions around the brachial plexus in the supraclavicular fossa. In a series of more than 150 cases $^{2}$ he found the method very valuable and safe in addition to those employed for inducing anesthesia for operations on the upper extremities. Other observer $s^{3}$ have also reported favorably on the method, most of them being exceedingly enthusiastic about its possibilities. American publications on the subiect have not been seen and it may therefore be permissible to describe the technic of Kulenkampff's method, some modifications, and the results obtained, before detailing a case of collapse following its administration.

The area for the injection of the brachial plexus is the space bounded internally by the subclavian artery, externally and below by the clavicle, in the depths by the upper surface of the first rib. Several guides for the point of introduction of the needle have been described. According to Kulenkampff, the continuation of the line of the external jugular vein, at a point immediately above the clavicle, is the site of election, because the subclavian artery lies internal to this line. Braun ${ }^{4}$ finds that the midpoint of the clavicle accurately locates the brachial plexus. There can be no doubt, however, that the subclavian artery should be the sole guide for the introduction of the needle. This is especially emphasized because there may be considerable variation in the position of the subclavian artery, and the use of the other guides may then be disastrous.

If possible, the patient is placed in a semireclining posture. His head is slightly turned away from the side to be injected. According to most observers, the skin at the site of introduction of the needle should be anesthetized. This appears undesirable to me, because the definition of the landmarks may be obscured. A fine needle, about $6 \mathrm{~cm}$. long, detached from the syringe, is employed. The position of the subclavian artery having been unquestionably determined, the needle is introduced immediately external to the vessel at a point directly above the clavicle. The needle is introduced slowly, and directed downward, forward and inward.

The best guide for the path of the needle is the spinous process of the second dorsal vertebra. The latter should be marked on the skin and the needle should be pointed directly toward the mark. In the great majority of instances the brachial plexus is reached at a depth of from 1.5 to $3 \mathrm{~cm}$. There is one unmistakable indication that the needle is at the plexus: paresthesias of varying intensity appear in the hand and arm. They may be in the territory of the median or of the radial nerve distribution, or in

* From the Surgical Department of the Mount Sinai Hospital Dispecsary.

1. Kulenkampff: Zentralbl. f. Chir., 1911, No. 40.

2. Kulenkampff: Beitr. z. klin. Chir., 1912, 1xxix, 550

3. Eberle: Arch. f. klin. Chir., 1912, xcix, 1020. Babitzki: Deutsch. med. Wchnschr., April 3, xxxix, No. 14, p. 652. Neil and Crooks: Brit. Med. Jour., Feb. 22, 1913. Braun: Die Lokalanaesthesie, Ed. 3, Bartl, Leipsic, 1913

4. Braun: Die Lokalanaesthesie, Ed. 3, 1913. both. Under no circumstances should fluid be injected until paresthesias have definitely appeared. Various concentrations of novocain solutions have been advised, the most generally employed being a 2 per cent. solution combined with epinephrin; 20 c.c. are ustually injected. If the paresthesias appear in the median nerve distribution alone, the needle should be introduced a few millimeters deeper for the injection of the second half of the fluid. The reason for this is the relatively superficial position of the median nerve in the plexus, at the site of injection.

The first rib lies in the path of the needle at a depth of from 1 to $5 \mathrm{~cm}$. If the needle misses the brachial plexus it should reach the first rib. Under these circumstances the needle must be withdrawn slightly and moved about a little in the effort to incite the typical paresthesias. The latter failing, the needle should be removed for, in avoiding the subclavian artery, it has probably been inserted too far out. There are no recorded cases of injury to the artery, and there is no likelihood of such an injury if the technic described above is closely followed.

The anesthesia of the upper extremity from injection of the brachial plexus is complete in most instances. It begins a few minutes after the injection,

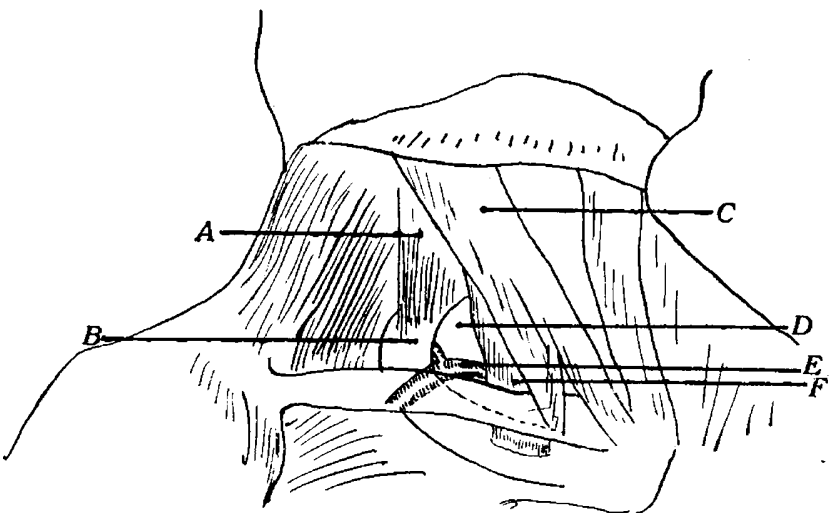

Fig. 1.-Diagram to show the relation of the first rib and the subclavian artery to the clavicle (modified from Kulenkampff): $A$, scalenus medius; $B$, first rib; $C$, sternomastoid; $D$, position of apex of lung; $E$, subclavian artery with transversalis colli; $F$, scalenus anticus.

with tingling and a sense of heaviness of the arm. The anesthesia generally develops in scattered patches but is complete in from five to thirty minutes. It is accompanied by a paresis of the extremity that is generally in direct proportion to the anesthesia. The loss of sensation involves the upper extremity to within 2 inches of the acromion, but sensation in a small patch along the inner aspect of the upper arm (intercostohumeral distribution) generally remains more or less intact. The anesthesia is of one and onehalf to three hours' duration. No sensory disturbances, either local or in the distribution of the plexus, have been observed.

When the anesthesia is complete, any of the operations on the upper extremity can be done. It is unnecessary to entmerate the various procedures carried ont by others and by myself; suffice it to state that all of the major operations have been successfully performed. It is of interest to note that fractures can bo reduced and operated on without pain under this anesthesia. Kulenkampff's method would not appear applicable to operation on the shoulder-joint, never-

5. The Braun formula for the combination is 1 c.c. epinephrin $1: 1,000$, to 50 c.c. 2 per cent. novocain solution. 
theless several dislocations of the shoulder have been painlessly reduced under brachial plexus anesthesia. Braun $^{4}$ reports an exarticulation of the shoulder-joint performed under it, local anesthesia of the skin in the line of the incision being added.

The anesthesia sometimes proves incomplete (in about 15 per cent. of the cases on record) and has even failed completely in a few instances. Nearly all observers agree that the proportion of unsatisfactory results steadily diminishes with increased experience.

Supraclavicular anesthetization of the brachial plexus has not been employed long enough, and the statistics are not sufficiently extensive (about 250 cases are on record) to state its advantages categorically. It appears indicated in all operations and all manipulations on the upper extremity for which local anesthesia, though indicated, cannot be readily and simply administered. Anesthesia of the brachial plexus has an unquestionably beneficial influence on shock. The following will serve as an illustration:

CASE 1.-A patient came under observation profoundly shocked from severely crushed wounds of the hand. Almost simultaneously with the appearance of anesthesia from the supraclavicular injection the signs and symptoms of shock began to lessen and soon were well-nigh gone. The exten-

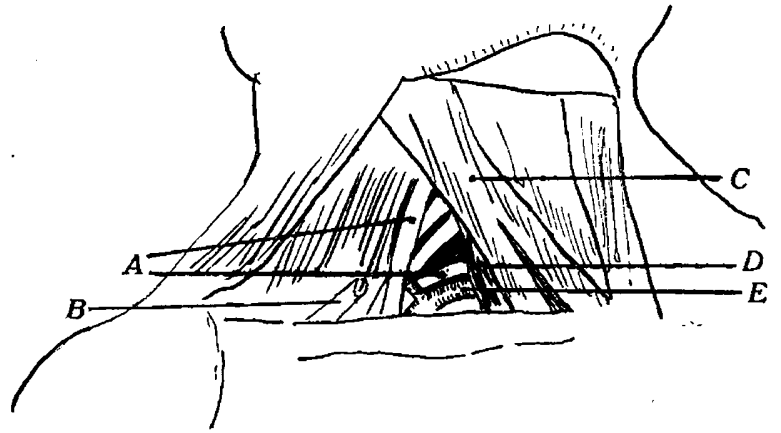

Fig. 2.-Diagram to show the relation of the brachial plexus to the clavicle and the subclavian artery (modified from Kulenkampff): $A$, $E$, subclavian artery.

sive operative procedures carried out on the hand did not effect any change in the greatly improved condition of the patient.

Furthermore, several observers believe that shock from operations under brachial plexus anesthesia is much less marked than that from such operations performed under general or local anesthesia; more studies must be made, however, before this can be established definitely.

Except for the statement that supraclavicular anesthesia may be incomplete, nothing has as yet been said of its disadvantages. Temporary paralysis of half of the diaphragm from involvement of the phrenic nerve has been reported several times. ${ }^{6}$ In one of these instances the paralysis persisted for more than a month and was accompanied by considerable difficulty in breathing. It appears impossible to determine the type of case in which paralysis of the diaphragm may occur, and I therefore believe that Kulenkampff's method is contra-indicated for patients suffering from pronounced intrathoracic disease. The only other reported complication referable to supraclavicular anesthetization is a single instance of musculospiral paralysis following its administration. ${ }^{7}$. An Esmarch

6. Sievers: Zentralbl. f. Chir., 1913, xxxvii, No. 10. Klauser and Stein: Ibid., 1913, xl, No. 16. Brunner: Ibid., 1913, x1, No. 28

7. Borchers: Zentralbl. f. Chir., 1912, xxxix, No. 26. band was employed for the very prolonged operation, and Borchers found it impossible to determine if the paralysis was the result of the anesthetization or of the pressure of the band. No instance of collapse following Kulenkampff's method has been reported and it is therefore thought advisable to present the following case:

CASE 2.-Mrs. F., aged 40, came under observation in the morning surgical clinic of Mount Sinai Hospital Dispensary, April 8, 1913. She had been well except for a stiff and painful shoulder of six months' duration. The thoracic examination being negative, Kulenkampff's anesthesia was planned for the operation. One per cent. novocain with epinephrin after the Braun formula (q. s.) was employed, the solution having been prepared under careful aseptic precautions. The needle was introduced into the right supraclavicular fossa in the typical way and its presence in the plexus determined by the very definite paresthesias complained of by the patient. The brachial plexus was found easily; indeed, at no stage were there any technical difficulties. Ten c.c. of the solution were then slowly injected. Within one minute the patient began to complain of a sense of oppression and wished to lie down. Her color became progressively more pallid and the mucous membranes pale. She went rapidly into a state of profound collapse. The pulse became very irregular, rapid, and poor in quality; at times it was almost imperceptible. The respirations were very labored. The patient vomited several times, coughed occasionaliy, and expectorated some blood-tinged sputum. She was very restless, and repeatedly expressed a fear that death was impending. Vigorous hypodermic stimulation was resorted to, but this appeared to have very little effect on the collapsed state of the patient. She was therefore transferred to the reception ward of the hospital. Here the foot of the bed was elevated, rectal saline infusion administered, and hypodermic stimulation given each time the heart action became alarmingly weak. About four hours after the supraclavicular injection the general condition began to improve slowly. The patient was then admitted to Dr. Nathan E. Brill's service (the First Medical Division) and I am indebted to him for permission to abstract the following hospital notes of the case: In the night codein was given for restlessness. Twenty-four hours later the condition of the patient approximated the normal. The examination of the heart and lungs was negative. The motor paresis and the cutaneous anesthesia of the right upper extremity had disappeared. There were a few hyalogranular casts, but no albumin in the urine. The patient complained of headache and nausea. April 10 (two days after admission), a slight rise in temperature (100.4) appeared, but was not accompanied by other manifestations. The patient was discharged, free from any after-effects of the collapse, April 12.

The collapse occurring in Case 2 can be ascribed to acute novocain poisoning or to trauma of the brachial plext1s. It is generally held that the toxicity of novocain is very low. Braun, ${ }^{4}$ in a large experience, has neither seen records nor encountered toxic effects from dilute (from 0.5 to 2 per cent.) solutions of the drug when injected subcutaneously, even when large amounts have been employed.

Symptoms of poisoning have been described, however, from the injection of from 20 to 25 c.c. of 2 per cent. novocain solution into the sacral canal (Laewen, ${ }^{8}$ Braun $\left.^{9}\right)$. They consisted mainly in nausea and sweating, pronounced pallor, a small and rapid pulse, accelerated respiration, repeated vomiting and a sense of oppression. These symptoms are paralleled by those of the patient in Case 2 which I have reported. In this connection it is of interest to note that von Gaza and Laewen have used large amounts of dilute (from 0.5 to 4 per cent.) novocain solution for blocking the

8. Laewen: Deutsch. Ztschr. f. Chir., 1905, lxxx, 180

9. Braun: Deutsch. med. Wchnschr., 1905, No. 42. 
nerves of the lower extremity. They found that the tolerance was greatly increased by injecting the fluid slowly (over a period of from ten to fifteen minutes). Nevertheless, toxic symptoms appeared in a few of their cases. It was stated in the preceding paragraph that trauma to the brachial plexus may have caused the collapse of the patient. There can be little doubt of a certain amount of injury from injecting from 10 to 20 c.c. of fluid into a close-meshed plexus of nerves. It is well known that external violence applied to the brachial plexus sometimes results in a symptom-complex similar to that of my case. Despite these suggestions for the tranmatic origin of the symptoms, it does not appear at all probable that injury was the cause of the manifestations. Were it so, collapse symptoms would be frequently observed. Besides, it is difficult to conceive the trauma profound enough to result in the symptoms in question. If all the flitid were injected into a single nerve-trunk, the trauma would possibly have been sufficient; the complete anesthesia of the arm. however, indicated that fluid was injected about several of the nerves. I must therefore conclurle that the collapse of the reported patient was most probably due to acute novocain-poisoning. although tratma cannot be absolutely excluded as the cause.

From the experience of others and my own limited trial of the method it may fairly be stated that supraclavicular anesthetization of the brachial plexus will prove an exceedingly valuable addition to the methods of regional anesthesia when serious complications from its administration can be eliminated.

1275 Madison Ave.

\section{BEST METHODS OF DISCOURAGING THE ACTIVITY OF INOPERABLE CANCER}

\section{A STUDY OF HEAT IN CANCER *}

\section{J. F. PERCY, M.D.}

GALESBCRG, ILL.

Among the earliest of the various procedures used in the treatment of malignant growths is the Chian turpentine advocated by Clay of Birmingham; there has been developed since then the molasses treatment; soap solution and ox-gall; cancroin, a poisonous product of cancer-tissue; thyroid extract; trypsin and amylopsin as strongly recommended by Beard; atoxyl by Skene Keith ; Reicher's injection of epinephrin into the tissues about carcinomatous growth; Spiess' "337," an anesthetic not on the market, similar in chemical structure to novocain, by which Spiess obtained brilliant results in the carcinomas of mice, and Uhlenhuth's injection of pyocyanase. And now, among the most promising, at least from the laboratory point of view, are the selenium and tellurium compounds of eosin introduced by Wassermann and based on the fundamental work of Ehrlich. With these can also be considered the use of the colloids of certain metals, especially silver, copper and gold, as described by Caspari, Neuberg and Loeb. Under this general subdivision may also be placed serotherapy, namely, the fetal autolysates of Fischera and emulsions of Levin and Babcock; organ extracts treated by the Roentgen

\footnotetext{
* Read before the Western Surgical Association, Dec. 19.20, 1913.
}

ray and autoserotherapy as described by Hodenpyl and I11. These methods have excited great interest from the point of view of the experimental laboratory. This has been especially true of the fetal autolysates of Fischera, which, from the scientific point of view at least, have much to commend them.

Among the rest may be mentioned the serum of animals treated with cancer by Jensen; autolysated sarcoma by Blumenthal; epinephrin and antivenin horse-serum of Greenbaum, and defibrinated blood by H. C. Ross and Bier. I purposely omit a bibliography as not being germane to the subject-matter, and would refer the reader to the status of carcinoma therapy as given in the Reports of the American Association for the Study of Cancer, 1913.

In spite of our wishes and hopes, all of these methods have proved to be inconstant in their effects, and therefore unreliable and disappointing. From the general agents used in attempts to destroy carcinoma, such as these just mentioned, we can pass to those employed locally. Among the first is probably arsenic, and its history is neither unimportant nor disappointing, although it has been badly used in many instances. With the arsenic, zinc chlorid, calcium carbid and acetone have also been employed.

The Roentgen ray has played an important part in the local treatment of cancer, and it is probable that it is destined to play a greater rôle if the work of Batum of Berlin and that of Kroenig and Gauss of Freiburg holds up its early promise. That the Roentgen ray will inhibit and destroy the carcinoma cell, or germ, under favorable conditions, there can be no reasonable doubt. There remains for the physicist only the problem of making the rays reach in an effective way the most inaccessible regions of the body, the habitat of cancer. ${ }^{1}$

Radium also comes in this category. In reference to this agent, all that can be said at present is to express the hope that at least half the enthusiasm shown by the few who have had the rare opportunity of using it in large quantities will prove to be justified by sulbsequent results. Various modifications of the electric current also deserve recognition in the local treatment of cancer. With these, as with the Roentgen ray, the problem is also one of sufficient penetration to destroy the pathologic tissue, and leave, with the least amount of damage, the uninvolved tissue-cells. There are many of these methods. The most attractive, and, perhaps, the most promising, is the so-called fulguration method of de Keating-Hart, and also his thermoradiotherapy method. The diathermy system of Nagelschmidt and the electrocoagulation developed by Doyen of France belong to this same type. That these are scientific and based on good theoretical, as well as experimental data, there can be no question.

Finally, we have, as a last hope in the management of inoperable carcinoma, the operative treatment so well set forth by Mr. Cecil Rowntree. ${ }^{2}$ The essence

1. Recently my attention has been called to a new and powerf Roentgen-ray tube deviserl by W. D. Coolidge, and described in the

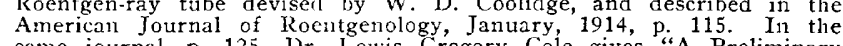
Ame journal, p. 125, Dr. Lewis Gregory Cole gives "A Preliminary Report on the Diagnostic and Therapeutic Application of the Coolidge Tube." He closes his report with the following: "With these forces under control, there is no limitation to the amount of ray at our command, and with the cross-tire method of application and the screen materially increased, there is every reason to hope that we may be able to apply to internal cancers the same amount of $x$-ray which, when applied to superficial cancers, has causet their immediate disappear plysicist had already made it possible for "the rays to reach in an effective way the most inaccessible regions of the body."

2. Rowntree, Cecil: Brit. Med. Jour., Sept. 27, 1913 